\title{
LA ALTERNATIVA NACIONAL POPULAR EN AMÉRICA LATINA
}

\author{
Octavio Humberto MORENO VELADOR ${ }^{1}$ \\ Carlos Alberto FIGUEROA IBARRA ${ }^{2}$
}

\section{Resumen}

En este trabajo los autores sustentan que ha habido una equivocada interpretación con respecto a la naturaleza de los llamados gobiernos progresistas en América latina. Desde la derecha tales gobiernos han sido calificados como "populistas", dándole a dicha categoría el sinónimo de mal gobierno. Desde algunos sectores de la izquierda, la caracterización que se hace es la de una versión más del neoliberalismo. En este trabajo, sostenemos que estos nuevos gobiernos están inscritos en un proceso revolucionario y tienen un carácter nacional popular. Dicho carácter se asienta en el precedente popular que los originó, el papel que le asignan al Estado, la forma en que conciben a la nación, la inversión social que hacen, la relación que establecen con los sectores populares y el tipo de integración latinoamericana a la que aspiran.

Palabras clave: Neoliberalismo, populismo, nacional-popular, revolución.

\begin{abstract}
In this work, the authors contend that has been a misrepresentation about the nature of the so called progressive governments in Latin America. Since the right wing these governments are qualified as "populists" meaning this category as synonymous of bad government. Among some leftist sectors, the representation is that such governments are a version of neoliberalism. In this article, we contend that these new governments are part of a revolutionary process and have a national-popular character. Such character is based in the popular precedent that originated these governments, the role in that them assign to the State, the form in that them conceive the nation, the social investment that they do, the

\footnotetext{
${ }^{1}$ Doctor en Sociología, Profesor de la Universidad Iberoamericana Campus Puebla.

${ }^{2}$ Doctor en Sociología, Profesor e Investigador del Instituto de Ciencias Sociales y Humanidades "Alfonso Vélez Pliego" de la Benemérita Universidad Autónoma de Puebla.
}

Fecha de recepción del artículo:Agosto 2014

Fecha de evaluación: Octubre 2014
\end{abstract}


relationship that establish with the popular sectors and the type of Latin American integration that they are looking for.

Keywords: Neoliberalism, populism, national-popular, revolution.

\section{Résumé}

Dans cet article, les auteurs affirment que la nature des soi-disant gouvernements progressistes en Amérique Latine est malentendu. La droite a classé ces gouvernements comme «populiste» les associant avec une catégorie synonyme de "mal gobierno". À l'autre extrème, des secteurs de la gauche, les caractérisent comme une autre version du néolibéralisme. Dans cet article, nous soutenons que ces nouveaux gouvernements sont engagés dans des processus révolutionnaires et ont aussi un caractère national populaire. Ces affirmations se basent sur l'appui populaire qui a aporter à l'État un caractère populaire; la façon dont le mouvements sociaux conçoivent la nation; les investissements sociaux realisé par les États, les relations établies avec les secteurs populaires et la nature de l'intégration qui'll cherche l'Amérique latine.

Mots-clé : Néolibéralisme, populisme, national-populaire, révolution.

\section{Introducción}

En este artículo presentamos una propuesta conceptual y analítica de los actuales procesos políticos que se presentan en países como Bolivia, Venezuela y Ecuador. Nos ocupamos de describir las pautas políticas y económicas principales que caracterizan a los gobiernos de izquierda de estos países y los denominamos como de tipo Nacional-Popular. Consideramos que el tipo de políticas económicas y sociales que propulsan los dotan de un carácter revolucionario, es decir, que tienden a generar transformaciones profundas en el status quo dominante. Este carácter transformador se concretiza a través de una serie de reformas que se han construido bajo las vías pacíficas, legales y gradualistas, aunque siempre sin perder de vista la creación de una correlación de fuerzas políticas que permita un control importante del poder de Estado a fin de poder continuar con el crecimiento de su proyecto. Partimos de la idea de que la revolución es ante todo un proceso en el que se construye precisamente esa correlación de fuerzas. En la medida en que en estos países se ha desplazado del gobierno (que no del Estado) a un grupo de fuerzas sociales que imponían el neoliberalismo, y que ese desplazamiento ha abierto la posibilidad de implantar un proceso posneoliberal con participación popular, en esa medida calificamos de revolucionarios a estos procesos.

Entendemos a lo Nacional-Popular como una forma de Estado y de gobierno nacional que posee su sentido fundamental en la asociación entre aparatos burocráticos, políticas estatales y las masas populares. La fuerza de este tipo de gobierno reside en la convergencia de múltiples organizaciones civiles y movimientos sociales con la institucionalidad estatal, desde su propia formación y en su funcionamiento burocrático. Este fenómeno se presenta típicamente en la organización de una estructura de "movimientos-partido" que posteriormente desemboca en una organización de tipo "movimientos-gobierno". 
Acorde con esta perspectiva consideramos la existencia de cuatro grandes ejes político-económicos que caracterizan a los regímenes nacional-populares, los cuales describimos y analizamos. El abordaje de estos siete aspectos a lo largo de las partes subsecuentes del artículo, organizados por temáticas y no por orden de importancia, cumple con mostrar lo que consideramos las políticas más importantes que en la actualidad se llevan a cabo dentro de los Gobiernos Nacional-Populares en Bolivia, Venezuela y Ecuador, y que los dotan de su esencia transformadora. Siempre considerando que, en tanto los regímenes Nacional-Populares se encuentran actualmente en desarrollo, el balance y resultado final de los procesos se encuentra abierto, existiendo la posibilidad de que existan vaivenes en su continuidad o bien en su proyección al futuro lejano. Siendo procesos que tienen su piedra angular en la constitución de contundentes mayorías electorales, su continuidad está lejos de ser garantizada.

\section{La alternativa Nacional-Popular en América Latina}

Como categoría para describir los procesos de cambio político en países como Venezuela, Bolivia y Ecuador, proponemos el concepto de Nacional-Popular. Este concepto posee su sentido fundamental en la cercanía existente entre gobiernos nacionales y los grupos y agregados populares, una asociación que han permitido un empoderamiento gradual de las estructuras de Estado por parte de la sociedad civil. Cabe decir que en estos procesos resultaron fundamentales los procesos de crisis y deslegitimación política que se originaron desde mediados de los años noventa en estos tres países, ante los cuales respondió la emergencia de una vigorosa actividad de la sociedad civil en estos tres países. Dicha actividad encontró su mayor fuerza en la organización de bloques de movimientos políticos y sociales en los que convergieron múltiples organizaciones civiles y políticas, las cuales hicieron posible el surgimiento de frentes electorales que impulsaron a candidatos de izquierda como Hugo Chávez, Evo Morales y Rafael Correa.

Estos frentes electorales dieron paso a una forma de organización de tipo "movimientos-partido" que posteriormente desembocaron en fenómenos de tipo "movimientos-gobierno". En consecuencia, consideramos que el cambio político actual en estos países se puede entender como una lucha que se ha librado no solo en el espacio de la institucionalidad propiamente estatal, sino desde el interior de la sociedad civil. De manera que tanto para los movimientos como para los gobiernos el objetivo último es la transformación del Estado y de las condiciones materiales de la existencia social. Considerando que la razón de que el Estado sea el objeto de lucha para las fuerzas de la sociedad civil tiene que ver con que, más allá de que exista una voluntad por reificar al Estado, o adoptar una postura Estado-céntrica, en las actuales condiciones el Estado sigue siendo una figura central de poder en los países latinoamericanos. En estos procesos el Estado es utilizado como una herramienta de transformación fundamental ya que estas fuerzas se mueven en contextos en los que existe oposición política que defiende proyectos enfrentados. En este sentido, el uso de la fuerza del Estado para evitar la secesión y la agresión directa interna, o bien para contrarrestar presiones externas económicas o políticas, resulta fundamental. 
Así, separándose de la posibilidad de que estos procesos sean una expresión de la llamada "revolución pasiva", entendida como: "el proceso de transformación "desde lo alto" en el que se recupera una parte de las demandas "de abajo", pero quitándoles toda iniciativa política autónoma" (Portantiero, 1981:44), consideramos más bien que en éstas se encuentra presente una lucha contrahegemónica. Entendemos ésta última, como un proceso de reconstitución de las clases políticas en Latinoamérica a través de una propuesta de resignificación identitaria proyectada hacia la conquista de los gobiernos nacionales. Un proceso donde lo nacional-popular se aboca por una reforma intelectual y moral sobre la política nacional para dotar de poder a las clases populares y los ciudadanos en general, y donde estos actúan como un gran conjunto de grupos independientes para apropiarse del Estado como un ente que anteriormente estuvo enajenado por grupos de poder político y económicos minoritarios. En síntesis y siguiendo los principios del pensamiento gramsciano, la búsqueda de un nuevo sentido de la acción histórica (Vilas, 1994:523-528).

Partiendo del hecho de que estos movimientos plantean como campo de lucha al propio Estado mediante su conquista gradual por la sociedad civil, encontramos una forma de lucha política que es esencialmente diferente de las propuestas de la toma del poder por la vía armada y la consecuente destrucción del entramado estatal. En estos la lucha de los movimientos político-sociales es por la conquista y cambio gradual del Estado, una lucha que plantea la reformulación del poder estatal a favor de las clases populares; concibiendo al Estado como un "organismo propio de un grupo destinado a crear las condiciones favorables para la expansión del grupo, pero este desarrollo y esta expansión son concebidos y presentados como la fuerza motriz de la expansión universal, de un desarrollo de todas las energías nacionales" (Gramsci, 1999:40). Por lo tanto, desde esta perspectiva es posible plantear a estas luchas como nuevas formas de transformación revolucionarias.

Estos son contenidos que se pueden apreciar en las reformas constitucionales realizadas en Venezuela, Bolivia y Ecuador, que generan condiciones muy diferentes a las existentes en los años previos a su llegada al poder. En el caso de Bolivia con la reforma constitucional indigenista, en Ecuador las reformas constitucionales dentro del margen de la "revolución ciudadana" y en Venezuela mediante la " Nueva Constitución" de 1999, todas ellas reformas que entran dentro de una concepción del derecho renovadora $\mathrm{y}$ transformadora, moldeando nuevas formas de Estado y de condiciones para el ciudadano. A través de las reformas constitucionales se han impulsado agresivos programas reformas amplias del poder estatal y de gobierno, entre los cuales sobresale la nacionalización de industrias clave, en especial en lo relativo a la industria de los hidrocarburos y en sectores claves de la producción de materias primas; reformas que "opera (n) esencialmente sobre las fuerzas económicas (...) (y sobre) el aparato de producción económica, que renueva la estructura", reformas que operan como parte de un proyecto global de transformación civilizacional (Gramsci, 1999:25).

De acuerdo con el sentido de transformación profunda que poseen los procesos Nacional Populares en países como Venezuela, Bolivia y Ecuador, planteamos la existencia de siete ejes de acción política estatal que dan cuenta tanto de las tendencias compartidas entre los casos como de la orientación de transformación que poseen. 


\section{La integración política ciudadana}

Un primer eje que comparten los casos analizados considera la presencia de una intensa participación popular tanto independiente como integrada orgánicamente al gobierno. Este tipo de regímenes han impulsado una serie de mecanismos de participación política social que complementan y potencian la democracia representativa existente. En específico nos referimos a la creación de instancias de participación política directa como lo son los mecanismos de democracia directa en Venezuela, Ecuador y Bolivia.

Esta participación política directa se encuentra orientada hacia la horizontalidad en la relación entre Estado y sociedad, a través de herramientas de democracia directa como lo son: los referéndums, los referéndums revocatorios, las consultas populares y la creación de un entramado institucional que favorece la acción directa de la sociedad en coordinación con el gobierno, como es el caso de los Consejos Comunales en Venezuela. Estos mecanismos de participación redundan en la construcción de democracias de tipo participativas, esta es una forma de democracia que tiende a romper la distancia entre el gobierno y las poblaciones nacionales y que se orienta a volver a los diferentes grupos de la sociedad civil agentes activos y decisores directos sobre la acción del Estado y el gobierno.

El primer producto de esta forma de integración entre la ciudadanía y el gobierno pasa por la forma como se han integrado las agendas de gobierno en los regímenes NacionalPopulares en Venezuela, Bolivia y Ecuador. En estos gobiernos las agendas políticas se han formado con base en las demandas de los grupos populares que respaldaron y fortalecieron a sus campañas políticas. En específico las políticas con respecto a temas como los hidrocarburos, las políticas de apoyo económico popular, de suministración de servicios básicos para la población, la administración y uso de agua, el uso y repartición de tierras, la creación de Asambleas Constituyentes para refundar a los Estados, la creación de mecanismos de democracia participativa, son políticas que tuvieron su punto de origen en las demandas de los propios movimientos sociales. Por tanto, las agendas de gobierno no se construyeron en una mesa de técnicos y burócratas, sino dentro del propio ciclo de movilizaciones sociales. En este sentido, los gobiernos han sido solo la vía para la construcción de alternativas y de políticas concretas de la sociedad civil (Natanson, 2007:166).

Sin embargo, la creación de políticas alternativas no se ha limitado a la mera conformación de las agendas de gobierno, sino que también se alimentan permanentemente a través de las herramientas y mecanismos de la democracia participativa. En este sentido, la integración de los diferentes grupos sociales se da en buena medida a través de la implementación de prácticas y mecanismos de democracia directa. Entendemos aquí a la democracia directa como

un grupo de instituciones políticas en las que los ciudadanos deciden o emiten su opinión en las urnas a través del sufragio universal y secreto y que no forma parte del proceso electivo regular de autoridades. (...) La condición sine qua non de todo mecanismo de democracia directa (...) radica en la votación propiamente dicha, en la cual todos los ciudadanos son iguales y en la que expresan más fielmente su potencia soberana (Altman, 2010:10). 
De acuerdo con esta definición, las herramientas empleadas por estos regímenes para ejercer la democracia directa son los referéndums y las consultas ciudadanas. A lo largo de los últimos años, los gobiernos Nacional-Populares han utilizado estas herramientas como una forma de integración de la voluntad ciudadana y como mecanismo de legitimación para muchas de las iniciativas que en no pocos casos iban en contra de los intereses y voluntades de los anteriores grupos dominantes.

En el caso de Venezuela tenemos como ejemplo el "referéndum revocatorio presidencial" del 15 de agosto 2004. En este referéndum se puso a decisión ciudadana la remoción del expresidente Hugo Chávez. El origen de este proceso fue la crisis política que se derivó del intento de golpe de Estado por parte de la oposición hacia el gobierno de Chávez en el año de 2002. Esta intentona resultó infructuosa gracias a la intensa protesta popular que se registró y la respuesta por parte de los partidarios de Chávez que permitió la vuelta del presidente. Esta situación de tensión política, que incluyó la amenaza de grupos conservadores de despertar una suerte de guerra civil, llevó al gobierno de Chávez a aceptar el referéndum revocatorio. Finalmente tras reunir 2,7 millones de firmas solicitadas constitucionalmente se hizo el llamado a referéndum, y este se celebró el 15 de agosto de 2004. El resultado de este referéndum fue un punto decisivo en el gobierno de Chávez, ya que se logró obtener un $58 \%$ a favor de la permanencia, quedándose la oposición con un 42\% (Febres y Márquez, 2006).

El siguiente ejemplo es el del referéndum constitucional de Venezuela en 2007. En esta ocasión fue Hugo Chávez quien decidió impulsar un proceso de referéndum con el objetivo de modificar 69 artículos de la constitución de 1999. Entre las iniciativas que se buscaba aprobar estaba la de incluir constitucionalmente al Estado venezolano como un Estado Socialista. De igual manera el proyecto incluía una propuesta para la ampliación de los poderes del Estado, y permitiría la reelección presidencial sin límite. También postulaba la creación de milicias populares llamadas bolivarianas; la conformación de un Poder Popular que seguiría el principio de sufragio universal, directo y secreto; una serie de procesos de recentralización político-administrativos; la elevación de los topes en el número de firmas necesarias para la convocatoria a referendos populares y una potestad especial del presidente para crear regiones especiales con fines estratégicos así como nombrar autoridades específicas para garantizar la soberanía y la defensa del territorio. A este conjunto de propuestas Chávez lo llamó una "radicalización de la democracia participativa" (López Maya, 2011:5). Finalmente el resultado de esta votación arrojó un resultado a favor del No por un margen de tan sólo 120.000 votos. Sin embargo, a pesar de ser una derrota para el chavismo, sobresale que la realización del referéndum reveló una voluntad de fortalecimiento del poder estatal y su proyecto con base en el apoyo ciudadano. En este sentido, el gobierno chavista se mostró como un gobierno que respetaba las decisiones populares a pesar de que fueran en contra de su propio proyecto (Lavaud, 2007:146).

En el caso de Ecuador desde las propuestas de campaña aparecía la reforma a la democracia como un eje fundamental en su propuesta política. En la agenda Alianza País, se planteaba la necesidad de impulsar una "revolución política" en la que se propugnara por la transformación y recuperación de la privatizada estructura estatal y el fortalecimiento de 
la democracia participativa junto con el mejoramiento del sistema de representación política. De acuerdo con este programa de campaña basada en una exigencia social, se organizó una "consulta popular" para impulsar la creación de una nueva constitución. La propuesta requería de crear una nueva Asamblea Constituyente con el fin de reformar la constitución de 1998. La consulta se realizó el 15 de abril de 2007 arrojando un voto de aprobación del $81.72 \%$ de la ciudadanía contrastando con un $12.43 \%$ que se manifestó en contra. Se eligieron un total de 130 asambleístas con una mayoría por parte del partido del presidente Alianza PAIS, quienes aliados con otros partidos de izquierda lograron formar una mayoría absoluta. Posteriormente, el proyecto de texto constitucional se sometió a consulta popular para que la ciudadanía votara a favor o en contra de adoptar la nueva constitución. Esta consulta se celebró el 13 de agosto de 2008 y para el día 16 de octubre se proclamaron los resultados definitivos, en los que el Sí obtuvo 63,3\% y ganó en 23 de las 24 provincias. Esta fue la primera vez, desde 1869, que una Constitución aprobada por una Asamblea Constituyente era discutida y votada por la población (Hernández y Buendia, 2011:134).

En el caso de Bolivia se celebró un "referéndum revocatorio" el 10 de agosto de 2008, en el que se decidía la posible dimisión del Presidente Evo Morales, del Vicepresidente Álvaro García Linera y de ocho de los nueve prefectos departamentales. Este referéndum, que fue impulsado por los grupos opositores de Morales, terminó ratificando al presidente, y su gabinete en el gobierno, ya que lograron obtener el 67,43\% de los votos a su favor. De igual forma los prefectos de los departamento de Chuquisaca, Oruro, Potosí, Tarija, Santa Cruz, Pando y Beni fueron ratificados, y los prefectos opositores de La Paz y Cochabamba terminaron siendo revocados. Al igual que en el caso de Venezuela, este referendo revocatorio fue impulsado por la oposición a sus gobiernos, sin embargo, los resultados de ambos referendos o consultas terminaron fortaleciendo a sus respectivos gobiernos, al despertar la participación y el respaldo de la mayoría de la ciudadanía.

También en Bolivia se celebró un "referéndum constitucional" el 15 de enero de 2009. Este proyecto se gestó desde el año 2006 cuando se realizaron elecciones para elegir a los integrantes de la Asamblea Constituyente de la cual emanaría una nueva constitución para Bolivia. En esta Asamblea terminó por dominar el bloque favorable al presidente Evo Morales con más de un $50 \%$ de los 255 escaños. Tras varios momentos de bloqueo por parte tanto del Congreso Nacional como de la Corte Nacional Electoral, el 20 de octubre de 2008 se convocó a una consulta para el 25 de enero de 2009. La nueva constitución resultó aprobada con un total de $61,43 \%$ de los votos, por sobre un $38,57 \%$ de votos en contra, y fue promulgada el 7 de febrero de 2009 .

En conjunto estos procesos de democracia directa son muestras del fortalecimiento de los gobiernos Nacional-Populares en cuanto a su constante interrelación con sus ciudadanos. Un aspecto que los hace diferentes respecto a las experiencias anteriores en cuanto a que si bien siguen considerando los mecanismos de la democracia representativa, el uso de los mecanismos de democracia directa permite mantener un flujo constante de comunicación y escrutinio entre la ciudadanía y sus gobiernos. Rompiendo de esta forma el fenómeno de delegación política propio de las democracias centradas meramente en las 
elecciones que reduce el papel del ciudadano a un mero emisor de voto en cada ciclo electoral para elegir nuevos funcionarios.

\section{La "inclusión material" Nacional-Popular}

Otro eje fundamental que distingue a los gobiernos y Estados Nacional-Populares son las políticas de integración socioeconómica de las mayorías populares, basada en la creación de una institucionalidad y fondos económicos destinados a dotar de bienes y servicios públicos como salud, alimentación y educación. En general este fenómeno puede ser entendido como una reapropiación de lo público por encima de los intereses privados, ya sean nacionales o internacionales, para lo cual es indispensable recuperar bienes y riquezas territoriales. En este sentido, lo Nacional-Popular propugna la creación de nuevos pactos nacionales en los que se coloca al interés ciudadano y la protección de las poblaciones nacionales como el elemento fundante o esencial de los estados nacionales.

En el caso de Bolivia, el gobierno de Evo Morales ha impulsado una ambiciosa campaña de transferencias de renta para atender a grupos sociales como niños, ancianos o mujeres embarazadas en el marco de la "Política de Protección Social y Desarrollo Integral Comunitario del Plan Nacional de Desarrollo". Los recursos que se distribuyen tienen su origen principalmente en las ganancias obtenidas por la explotación de hidrocarburos, una industria que fue recuperada y ahora funciona como el respaldo de la política social del gobierno de Morales. Otro ejemplo de estos programas es Renta Dignidad, un programa de transferencia de rentas para todos los adultos con más de setenta años. Este programa tuvo su antecedente en los años noventa durante el gobierno de Gonzalo Sánchez de Lozada a través del llamado Bonosol, y en la actualidad se ha extendido con un monto de doscientos bolivianos (equivalente a treinta dólares) mensualmente (Stefanoni, 2011:36) (Aponte, 2006:65). De igual manera, para atender a la niñez se creó el programa Juancito Pinto que consiste en un pago de treinta dólares anuales a los alumnos de escuelas primarias públicas por el solo hecho de mantenerse como estudiantes en el sistema educativo. O bien, también se crearon el bono Madre, Niño y Niña Juana Azurduy que consiste en una transferencia de cincuenta bolivianos (aproximadamente siete dólares) por cada control médico, hasta un máximo de cuatro ocasiones. Aunado a este apoyo también se otorgan 120 bolivianos (diecisiete dólares) por cumplir con los controles médicos de niños y niñas menores de dos años. El objetivo de este último programa es reducir los índices de mortalidad materna infantil.

En términos de indicadores socioeconómicos los resultados logrados por el gobierno boliviano han sido importantes. Basta considerar algunos indicadores generales para demostrar esto: el ingreso per cápita para 2011 había subido a 1.833 dólares y para 2012 había subido hasta los 2.232 dólares, en comparación con los 942 que tenía en 2001; en el período entre 2005 y 2010 la pobreza urbana se redujo del 60,6\% al 49,6\%; la pobreza rural se redujo del 77,6\% al 65,1\%; la pobreza extrema en general bajó del 38,2\% al 25,4\%, y la pobreza extrema en el campo bajó de $62,9 \%$ a 44,7\%. De igual manera, la inversión pública estatal pasó de 600 a 3.300 millones de dólares, de los cuales el 66\% se invirtió directamente en el área rural (Stefanoni, 2011:38). Además estas políticas de transferencias $\mathrm{y}$ de inversión pública, el Estado boliviano ha reformado sus constituciones e instituciones 
a fin de proteger los derechos laborales y sociales. En este sentido el Estado ha reestatizado el sistema de pensiones, privatizado durante los años noventa, y ha derogado la subcontratación de trabajadores legalizada durante los año noventa.

De igual forma que en el caso boliviano, en Venezuela durante los últimos diez años se lograron progresos muy importantes en términos de lo que llamamos la inclusión material de sus ciudadanos. En principio se conceptualizó desde el documento "Las Líneas Generales del Plan de Desarrollo Económico y Social 2007-2013”. En específico en la sección Democracia Protagónica y Revolucionaria se plantea que el Estado se debe comportar como un ente fundado en la conciencia ética por encima de la fuerza, y que no admite que los intereses particulares se sobrepongan a los intereses generales de la sociedad y el bienestar de todos (Monsalve y Gabaldón, 2012:511). En este sentido, es notorio como se dota al Estado de un sentido fundado en el interés general de la sociedad por encima de los intereses particulares.

Los recursos que hacen posible la dotación de bienes y servicios provienen en buena medida del ingreso fiscal petrolero, destinados para hacer posible el funcionamiento de los consejos comunales, de las políticas sociales y de las llamadas Misiones. Esta política de redistribución y en general la expansión económica posibilitada por el Gobierno chavista, comenzó cuando se obtuvo el control completo sobre la empresa nacional del petróleo Petróleos de Venezuela (PDVSA) en el primer trimestre de 2003. A partir de este momento el PIB se incrementó casi al doble en diez años, al crecer a un ritmo anual del 13.5 por ciento. De manera contraria a como asumen muchos de sus críticos, este crecimiento se ha dado sobretodo en el sector no petrolero, y específicamente el sector privado ha crecido mucho más que el sector público (Weisbrot, Ray y Sandoval, 2009: 3).

En términos globales las políticas económicas y sociales inclusivas del régimen chavista tuvo éxitos espectaculares en cuanto a la reducción de la pobreza. Según el Instituto Nacional de Estadística (INE) para 2009 el índice de pobreza se había ubicado en $28.5 \%$ que representa una caída de quince puntos ante el $43.5 \%$ que había en 1999 . También la pobreza extrema se redujo en diez puntos porcentuales al pasar de ser de $17.1 \%$ en 1998 a 7.9\% en 2009 (Rodríguez, 2010:200). El gasto social por persona se incrementó por más de tres veces entre 1998 y 2006. De igual forma, entre 1998 y 2006, la mortalidad infantil disminuyó por más de un tercio. El número de doctores de atención primaria en el sector público se multiplicó por 12 veces entre 1999 y 2007 (Weisbrot, Ray y Sandoval, 2009: 3). La capacidad adquisitiva de los trabajadores mejoró sustancialmente en el período entre 2004-2007, y especialmente la de aquellos sectores con menos ingresos, gracias a los incrementos del salario mínimo decretado por el gobierno. El índice de remuneraciones en 2013 al compararlo con el de 2007 refleja una mejoría del salario promedio real del $18.33 \%$, lo cual lo pone como el mayor salario mínimo en América Latina, al ascender a un total de 636 dólares mensuales, por encima del salario en Argentina que se encuentra en los 310 dólares mensuales (Rodríguez, 2010: 198). En términos globales el gasto social se ha elevado en un $14 \%$ en los últimos veinte años, y en un $42 \%$ a partir del año 2000 , tan sólo para 2010 el proyecto presupuestario preveía una inversión para el área social del 45.7\% del total del presupuesto nacional, a distribuirse en áreas de salud, educación y seguridad 
social, entre otros sectores. Tan solo en 2009 para la salud la inversión total fue de 12028 millones de bolívares, lo que equivale al 7.2\% del producto interno bruto (Rodríguez, 2010:200).

En el caso venezolano se ha impulsado una serie de ambiciosos programas de asistencia social llamados "Misiones". La diversidad de áreas que cubren es amplia y todas están orientadas a satisfacer necesidades básicas de la población contando con su participación activa. Estas cuentan también con su propia estructura institucional paralela a la institucionalidad tradicional, en la que se insertan de manera efectiva la organización y participación de las comunidades en la gestión de los servicios (González, 2006:163). En concreto se lanzaron las Misiones Robinson I y II, orientadas a erradicar el analfabetismo y permitir concluir estudios básicos a la población adulta; la emblemática Misión Barrio Adentro I dedicada a brindar de atención médica básica a los habitantes de los barrios populares con la participación de personal médico cubano; Misión Mercal destinada a brindar a alimentos subsidiados a los sectores populares, según datos oficiales este programa alcanza hasta a la mitad de la población en el país; Misión Identidad destinada a brindar un documento de identidad a todos los ciudadanos; la Misión Guacaipuro que busca generar condiciones adecuadas para que la población indígenas pueda reclamar y disfrutar de sus derechos; la Misión Cristo destinada a combatir la pobreza extrema; la Misión Milagro destinada a ofrecer servicios oftalmológicos; La Misión Sucre y Rivas destinadas a impulsar la educación secundaria y universitaria (López Maya, 2010:207-208) (López Maya, 2011:10) (Alvarado, 2004). Según estudios recientes las Misiones han tenido un impacto importante en el bienestar de la sociedad venezolana ya que para 2006 un programa como Mercal tenía una cobertura del 50\% de la población y la misión Barrio Adentro que alcanza a un 30\%; de igual manera para 2007, de acuerdo con datos de la Encuesta de Presupuesto y Gastos Familiares, el 48\% se beneficiaba de al menos una de las misiones (D'Elia y Quiroz, 2012).

En el caso de Ecuador, nuevamente los recursos provenientes de los ingresos petroleros, una política fiscal progresiva (una medida que no se impulsado en profundidad en Bolivia y Venezuela) y los recursos obtenidos gracias a la renegociación de la deuda externa ecuatoriana, han permitido impulsar programas de atención social y un agresivo programa de subsidios a productos básicos (Correa, 2012:93). Así, desde el eje programático de Alianza País en 2007 se postuló la necesidad de impulsar una "revolución social" que buscara lograr igualdad y equidad entre los diferentes sectores sociales y las diversas identidades étnicas nacionales (Hernández y Buendía, 2011:136). Uno de los programas con mayor proyección es el llamado Bono de Desarrollo Humano que se otorga a familias de pocos recursos, un bono que ya existía desde antes del gobierno de Correa pero que se ha extendido a una mayor cantidad de gente, el monto de este bono asciende en la actualidad hasta unos 35 dólares mensuales. También existen una serie de programas como créditos para vivienda, para pequeños emprendimientos productivos, para educación, para salud. Además existen subsidios constantes al gas doméstico, a la gasolina, y a servicios públicos. Entre estos subsidios a servicios públicos se encuentra la llamada "Tarifa de la Dignidad" enfocada al servicio de electricidad, además de subsidios directos a insumos como la harina de trigo, los agroquímicos, la urea, así como sobre el precio de 
productos de la canasta popular como arroz, maíz, leche y pan. Otros ejemplos de las políticas de integración socioeconómica son la eliminación de costos a las consultas médicas, así como el otorgamiento de medicamentos básicos gratuitos aunado a un aumento en la jornada de atención a ocho horas. Un programa que sobresale dentro de la agenda es la promoción de la educación superior bajo condiciones de absoluta gratuidad desde 2008, que ha permitido que en la actualidad se haya elevado sustancialmente el número de estudiantes indígenas y afro-ecuatorianos, al elevarse de 15,000 a 204,000 inscritos.

En conjunto el gasto social en el gobierno de Correa se ha incremento de un $18 \%$ entre 2004 y 2006 hasta un $24 \%$ en 2012, posibilitando que la pobreza se haya disminuido de $37 \%$ en 2006 a un $33 \%$ para mediados de 2010 , y la pobreza extrema de $16 \%$ a $14 \%{ }^{3}$ De igual manera, según datos oficiales, el gasto entre 2009 y 2012 ascendió a 74,000 millones de dólares, una cifra que equivale a lo que se gastó en los 14 años anteriores a la llegada de este gobierno (Stefanoni, 2012:62-63). Sin embargo, en la perspectiva de Rafael Correa el otorgamiento de este tipo de apoyos no es suficiente para garantizar la salida de la pobreza para mucha gente sino que "las oportunidades son las que pueden acabar con la pobreza, y el hecho de que la gente pueda ahora ir a la universidad, esa educación ha sido democratizada, esto significa una gran oportunidad en términos de oportunidades" (Correa, 2012:98).

\section{El Estado Interventor, las economías mixtas y el horizonte poscapitalista}

Un elemento esencial que caracteriza a los Estados Nacional-Populares y sus gobiernos es el rescate del Estado como una herramienta de transformación y al servicio de las mayorías populares. Por tanto, el Estado ha dejado de ser una herramienta al servicio exclusivo de los poderes económicos y políticos transnacionales y se ha dotado de contenidos políticos y sociales asociados con principios de acción política como lo nacional y lo popular.

Si bien no aparece en las agendas de estos gobiernos Nacional-Populares la extinción del Estado en sí, existe una transformación profunda que ambiciona la reformulación del poder en el sentido de reapropiación del poder por parte de las mayorías nacionales. Un ejemplo claro de esto es que este se ha redireccionado para volverse un agente activo en la regulación y transformación de las relaciones de dominación no sólo políticas, sino también económicas.

\footnotetext{
${ }^{3}$ De hecho podemos agregar datos más recientes y contundentes, como los expresados por el presidente Correa en su discurso ante el V Foro Regional de Esquipulas en Guatemala. La pobreza en América latina es fruto de la inequidad y esto de las perversas relaciones de poder que favorecen a las minorías dijo Correa. Y agregó que se había disminuido un 8\% la concentración del ingreso mientras Ecuador había crecido 4.3\% en los últimos años. Entre 2006-2013 la pobreza cayó de 37.6 al 25.6 y la extrema pobreza se ubica por primera vez en la historia en menos de dos dígitos de 16.9 al 8.6\%. Rafael Correa, Discurso pronunciado en el V Foro Regional de Esquipulas en Guatemala, el 19 de agosto de 2014.
} 
Así, podemos hablar de la existencia de un Estado interventor Nacional-Popular que se ocupa de ofrecer una mayor seguridad y defender el bienestar de las personas, recuperando su obligación de proteger a los ciudadanos frente a las incertidumbres provocadas por la globalización neoliberal. Asimismo han tomado las riendas de la dirección económica en sus Estados a través del uso de recursos públicos para impulsar la actividad productiva interna, a través de la construcción de infraestructura, de apoyo a la producción de bienes y servicios básicos, bajo una estrategia que se aproxima al desarrollismo de los años cincuenta (Pizarro, 2005:139) (Stefanoni, 2011:26).

En este contexto el Estado interventor Nacional-Popular se preocupa por ser un ente incluyente para el bienestar y obtiene esta capacidad mediante una pugna directa por la retención del excedente productivo, principalmente el que proviene de la explotación de los recursos naturales y aquel que obtiene mediante el impulso a las industrias estratégicas nacionales. En este proceso la influencia de los movimientos sociales es fundamental ya para numerosos políticas la vía de aplicación de recursos se da mediante su propia estructura, aunque siempre respaldada y posibilitada por el propio Estado (Natanson, 2007:165). Consideramos que las tareas fundamentales que persiguen los Estados Nacional-Populares y sus gobiernos, posibilitadas por un modelo de Estado Interventor son:

I) volver al mercado interno el centro dinámico de la economía,

II) revertir el proceso de concentración de la riqueza y eliminar la pobreza extrema,

III) hacer una ruptura con el neoliberalismo y un distanciamiento de instituciones económicas internacionales como el BM y el FMI,

IV) convertir a las políticas macroeconómicas en una herramienta de desarrollo ampliado, y no en la camisa de fuerza para el bienestar colectivo que se convirtió durante el neoliberalismo.

De acuerdo con estas tareas consideramos que es fundamental para estos Estados y sus gobiernos el cuidarse de un problema como el sobreendeudamiento externo e interno, un problema que en buena medida provocó la implosión de los Estados Populistas de mediados del siglo XX (Soto, 2013:74-75). En este sentido, el reto no es mantener un déficit en ceros, sino en poder utilizarlo como una herramienta de desarrollo pero siempre vigilando que este sea moderado y manejable. Para crear empleo y estimular la actividad productiva se estimulan las exportaciones, se apoya el desarrollo técnico-científico, y se presta apoyo a los pequeños empresarios (Pizarro, 2005:136).

La presencia de un Estado Interventor ha posibilitado el control de la economía, la presencia del Estado como agente de desarrollo económico, la multiplicación de industrias y fábricas nacionalizadas, aunque también se encuentran presentes una cantidad importante de capitales privados nacionales e internacionales. En este sentido, se puede decir que actualmente el modelo económico que se sigue en estos tres países es el de una "economía mixta", en la que coexisten capitales privados conjuntamente con un Estado Interventor que guía la vida económica pero que es también un agente económico activo. Una economía mixta en su composición pero que se encuentra dirigida desde el Estado bajo los principios de inclusión de las mayorías populares. 
Si bien para muchos analistas y académicos este es un carácter que debería ser superado mediante la radicalización inmediata de los procesos, en la realidad estos gobiernos Nacional-Populares han asumido a la tarea de crear un nuevo modelo económico como una tarea acumulativa y de largo plazo. En este sentido, cabe considerar que estos gobiernos han tomado un cariz pragmático dado que lo que han hecho es moverse en favor de la transformación profunda de la situación económica en sus respectivos países pero sin perder de vista la situación internacional y las limitaciones que esta impone para conseguir la transformación. Es por esta razón que en la actualidad es posible apreciar estos modelos mixtos, que han generado transformaciones importantes respecto a los resultados de las políticas neoliberales.

En síntesis podemos decir que estos Estados Nacional-Populares y sus gobiernos sin renunciar a la ambición de crear un nuevo modelo económico completo, pero con los pies bien firmes en la realidad, se han abocado a asumir el proceso de transformación como un proceso largo en el que poco a poco se irán formando las alternativas del futuro. Una muestra de esto es la existencia de alternativas que se han creado en estos países como "el buen vivir", una propuesta que apunta a la construcción de alternativas poscapitalistas, o bien la todavía difusa propuesta del "Socialismo del Siglo XXI". Ambas propuestas que son alentadas por los gobiernos Nacional-Populares en busca de una futura transformación radical.

El rescate del llamado desarrollismo como una política de Estado, ha despertado la crítica de numerosos intelectuales que señalan como un grave problema el volver a este tipo de políticas. Esta crítica se basa en la idea de que dadas las condiciones globales actuales y el fuerte compromiso que actualmente se tiene con el calentamiento global y la contaminación atmosférica, volver al camino de la industrialización y el desarrollo, sería francamente cooperar con esta problemática. Sin embargo, lo que omiten estas críticas es el hecho de que buena parte de la economía mundial no ha parado en su dependencia de la producción industrial, y en este sentido la decisión de abandonar la generación de riqueza mediante la vía industrial significaría privar también de trabajo y recursos a las poblaciones de los Estados Nacional-Populares. Por otro lado, en estos países se llevan adelante también proyectos y alternativas al desarrollo capitalista todavía dominante a través de proyectos como los del "buen vivir", que propulsan una forma alternativa de entender el bienestar y el equilibrio con la naturaleza. En todo caso que estas alternativas tengan éxito depende de un desarrollo de estas propuestas en el largo plazo y de las condiciones a nivel global en la economía y la organización social. Por lo tanto, pedir a estos gobiernos que abandonen sus aspiraciones de una nueva ola de desarrollismo, es pedir también que renuncien a sus proyectos de generar bienestar mediante la creación y distribución de riqueza. Más aún en las condiciones actuales la ideología del "buen vivir" dista todavía mucho de ser una perspectiva compartida por las mayorías poblacionales, el que esta se vuelva un contenido

\footnotetext{
${ }^{4}$ En realidad no solamente la propuesta del socialismo del siglo XXI muestra dificultades en su formulación. Como lo formularemos líneas adelante, también acontece así con la del "buen vivir" en tanto que pueden tener connotaciones distintas cuando la expresan los gobiernos y cuando la expresan sus oposiciones de izquierda. El "buen vivir" en boca de la oposición de izquierda no expresa mucho sobre las correlaciones de fuerza a nivel mundial y nacional para llevar a cabo su proyecto.
} 
hegemónico depende de un proceso largo que solo puede ser emplazado por los Estados Nacional-Populares en el futuro próximo.

Además de esta crítica también se ha postulado que la dependencia de recursos provenientes de la primario-exportación ha generado una situación de "neoextractivismo" en estos Estados. Esta dependencia se ha argüido desde que los recursos que han hecho posible la inclusión material en los Estados Nacional-Populares provienen de la explotación de recursos naturales, y especialmente de los hidrocarburos. A este respecto un autor como Eduardo Gudynas (2009) ha sostenido que estamos ante la presencia de un "neoextractivismo del siglo XXI", una estrategia de desarrollo que se caracteriza por:

1) mantener la importancia de los sectores extractivistas como un pilar relevante de los estilos de desarrollo,

2) mantiene los atributos del extractivismo clásico,

3) mantiene la inserción internacional subordinada y funcional a la globalización comercial y financiera,

4) genera fragmentación territorial, con áreas relegadas y enclaves extractivos asociados con los mercados globales,

5) se mantienen los impactos ecológicos producto de la explotación,

Sin embargo, el propio Gudynas reconoce que estas problemáticas están mediadas por la presencia de un Estado que es más fuerte y que controla la explotación de estos recursos y su comercialización; por un Estado que también logra captar una mayor proporción del excedente generado por los sectores extractivos, recursos con los que se financian programas sociales. Estas características resultan fundamentales en la distinción entre el "extractivismo" de los Estados Neoliberales-Procedimentales y el de los Estados Nacional-Populares y no deben ser minimizadas.

En efecto los problemas y las limitaciones del extractivismo se encuentran captados por las apreciaciones de Gudynas, sin embargo sostenemos que esta situación se debe leer de acuerdo a una perspectiva de largo plazo, en el entendido de que la dependencia de los recursos naturales es un problema histórico en los Estados Latinoamericanos, y esta situación no puede verse resulta en el corto plazo. Por el contrario, la salida de esta situación depende de un proceso largo de replanteamiento de la estrategia de desarrollo o bienestar, una situación que solo se puede construir en el futuro. En este sentido, también aplica el reconocer que pedir a los Estados Nacional-Populares que renuncien a la explotación de su riqueza natural, es también pedir que pongan fin a sus programas de atención social. En todo caso, lo que sí se puede pedir a estos proyectos es que no repitan los errores históricos en el sentido de volver se economías dependientes de un solo sector y que se avoquen a enriquecer las fuentes productivas de riqueza. Una situación que nuevamente solo es posible si se aprovechan adecuadamente los recursos que provienen de la explotación de estos recursos y se direcciona adecuadamente a los sectores productivos apoyados por el Estado.

El reto en este sentido es la inversión en los mercados internos, en la ampliación de la capacidad de compra de las personas, una situación que permitiría integrar al sector exportador con la producción nacional. En la creación de incentivos que permita desarrollar 
y diversificar la producción interna y su vinculación con los procesos exportadores, posibilitando transformar los recursos naturales en bienes con un mayor valor de retorno (Acosta, 2010:46).

\section{Independencia, nación e integración regional}

En la actualidad los Estados Nacional-Populares han reafirmado en los hechos su condición como independientes respecto a los poderes económicos y políticos transnacionales de índole neoliberal o abiertamente imperialistas. Además estos también han propulsado una agresiva agenda en favor de la integración regional de los países sudamericanos que comparten el interés en construir una alternativa a la hegemonía geoestratégica de los Estados Unidos de Norteamérica en la zona.

Esta política de reafirmación de la independencia nacional resulta de especial contraste con la situación dominante durante el neoliberalismo en los que la soberanía nacional se vio en entredicho dado el control tan importante que poseían los intereses de capitales nacionales e internacionales, además del poder de instituciones trasnacionales como el Fondo Monetario Internacional o el Banco Mundial. A este respecto los Estados Nacional-Populares y sus gobiernos han protagonizado diferentes pugnas con los poderes políticos y económicos internacionales a fin de mantener su soberanía y reafirmar su independencia.

A este respecto un gobierno como el de Chávez encabezó por un buen tiempo la defensa de la soberanía venezolana especialmente en contra de la política injerencista de los Estados Unidos. Esta política injerencista se presentaba en áreas como el comercio, las inversiones productivas, en la producción petrolífera del país y la cooperación militar que se tenía con Venezuela (que incluía una base militar en Fuerte Tiuna) (González, 2006:163). Esta alteración de las relaciones que históricamente tenía Venezuela con Estados Unidos terminó por provocar en el corto plazo un antagonismo pronunciado entre ambos países.

Un aspecto muy importante en este proyecto de integración pasa por la posible creación de una alianza militar de defensa compartida. Este proyecto se propaló desde el año 2000 en la llamada I Reunión de Cúpula de los Presidentes de América del Sur, un proyecto que propuso la integración de las Fuerzas Armadas de la región ante posibles amenazas al territorio continental. En el año 2006 esta propuesta fue presentada por Chávez bajo el nombre de Consejo de Defensa Sudamericano, que estaría compuesto por los 12 países del subcontinente, una organización que se aproximaría al modelo de la Organización del Tratado del Atlántico Norte (OTAN), pero con el membrete de Organización del Atlántico Sur (OTAS) (Suzart de Pádua y Kalil, 2010:58). A pesar de la insistencia de Chávez, este proyecto no ha llegado a concretarse y dista mucho de tener un consenso en la zona.

Un gobierno como el de Bolivia ha mantenido una línea moderada al respecto, ya que si bien ha tenido numerosos desencuentros con la política oficial norteamericana y especialmente con la representación diplomática de los Estados Unidos en el país, en algunos momentos ha optado por mantener una línea independiente. Como ejemplo 
tenemos la defensa que ha hecho de la Comunidad Andina de Naciones (CAN), una organización que considera dentro de su organización a países como Perú y Colombia, ambos países con gobierno que han manifestado sus diferencias con la política exterior venezolana antiestadounidense y que firmaron tratados de libre comercio con los Estados Unidos. Esta decisión del gobierno Bolivia se debe principalmente a que en el espacio del CAN, Bolivia coloca el 40\% de sus exportaciones no tradicionales (Stefanoni, 2007:57).

Un área en la que el gobierno de Bolivia se ha visto más activo es la relativa a la creación de un proceso de integración energética, ya que este es un país con una producción gasífera importante. Por ello les resulta importante poder ampliar tanto su producción como el volumen exportable, a países como Brasil y Argentina, ya que en la actualidad se exportan más de 38 millones de metros cúbicos por día. Para poder ampliar este comercio sería necesaria la construcción de un gasoducto con una inversión estimada en 1,200 millones de dólares. Así, Bolivia ha desempeñado un papel muy activo en el diseño del Gasoducto del Sur, un proyecto muy ambicioso que busca conectar la futura producción venezolana de Maracaibo con el puerto de Buenos Aires, a un costo estimado entre 18.000 y 200.000 millones de dólares para un trayecto de 9.000 kilómetros (Stefanoni, 2007:78).

Así, a pesar de la existencia de diferencias entre las políticas de los diferentes Estados en América Latina, y en especial de los Estados Nacional-Populares, bien puede decir que hoy en día se puede observar una tendencia a favor de la integración, de acuerdo a un enfoque estratégico regional. Estas propuestas van más allá de los proyectos de integración económica que se impulsaron durante los gobiernos neoliberales, los cuales se reducían al mero establecimiento de tratados y pactos de libre comercio. Por el contrario en esta nueva situación la integración se plantea en términos de una integración estratégica que incluye aspectos políticos, sociales y económicas. Dentro de esta tendencia la Unasur representa una expresión muy importante de este nuevo regionalismo, ya que aspira a ser una respuesta efectiva ante los problemas de la integración latinoamericana y el desgaste de la política que dominó durante los gobiernos Neoliberal-Procedimentales.

Así, la Unasur posee seis puntos clave según el análisis de Sanahuja (2008)

a) el predominio de la agenda política sobre la agenda comercial, en coherencia con las visiones de los gobiernos progresistas y de centro-izquierda de la región; b) la recuperación de la agenda del desarrollo, desplazando a las políticas del Consenso de Washington y distanciándose de las orientaciones del regionalismo abierto; c) el retorno del Estado frente al protagonismo del sector privado y las fuerzas del mercado dominantes en el modelo anterior; d) una mayor énfasis en la "agenda positiva" de la integración centrada en la creación de instituciones y la promoción de políticas comunes, junto con una cooperación más intensa en ámbitos no comerciales; e) mayor preocupación por las carencias de integración física regional, con el objetivo de mejorar la articulación de mercados nacionales; f) mayor relevancia dada a las dimensiones sociales de la integración y al tratamiento disparidades y asimetrías interestatales y subnacionales, vinculando la integración regional con los objetivos nacionales de reducción de la pobreza y de desigualdad (22-24).

Por tanto, la Unasur puede ser tomada como como el proyecto estratégico más ambicioso de integración sudamericana, ya que también aspira a ser un foro en el que se reconozcan 
problemáticas comunes, la defensa de recursos geoestratégicos y la búsqueda de consensos ante coyunturas desfavorables (Chaves, 2010:30) (Pizarro, 2005).

\subsubsection{Las naciones de naciones. Estado pluriétnico y multinacional.}

En los Estados Nacional-Populares se ha llevado a cabo una profunda transformación en cuanto a la conceptualización que se tiene sobre la nación y sus características. Dicha transformación se debe a la fuerte presencia y protagonismo que han cobrado las diferentes etnias, naciones e identidades en Bolivia, Ecuador y Venezuela. Una situación que ha provocado que la idea de nación dentro de estos Estados se haya reconceptualizado a favor de la inclusión de los diferentes grupos y se haya modificado para que resultara inclusiva de la pluralidad étnica, ideológica y cultural que habita en cada uno de ellos.

En este sentido, el Estado Nación ha dejado de ser monocolor, ha dejado de ser pensado como producto de un solo grupo cultural, racial o social, y se ha transformado en una multiplicidad de naciones, en naciones de naciones, que habitan con iguales derechos en un mismo Estado. Cabe decir que en los casos de Bolivia y Ecuador este aspecto por sí solo representa una revolución cultural en plenitud, dado que históricamente lo indígena estuvo relegado a ser un grupo invisibilizado, subalterno y sujeto a los dictados de la nación blanca que dominaba no solo la política, sino en general todas las directrices del Estado. Por tanto, la emergencia de las naciones de naciones representan una franca muestra de la profundización de la democracia que rebasa por mucho los límites de la democracia procedimental, y que apunta a superar la histórica tradición del colonialismo interno. Los alcances de esta revolución nacional identitaria han llegado hasta los propios textos constitucionales de los Estados. Acaso el ejemplo más claro de esta situación lo encontramos en Bolivia, ya que a partir de 2007 y con refrendo popular en 2009, se lograron cambiar varios artículos claves para el impulso de esta transformación.

La constitución boliviana de 2007, generó una ampliación de los derechos políticos y sociales, los individuales y colectivos, además de incluir los caracteres plurinacional y comunitario del Estado. Gracias a estas reformas se permitió la inclusión con total legitimidad de las "36 naciones originarias" que conforman Bolivia, con reconocimiento formal también a su idioma, costumbres, sus zonas de asentamiento, y que reconoce también la oficialidad de su idioma para cualquier asunto asociado con la burocracia estatal. La expresión más acabada de esta situación está en el reemplazo del Estado Unitario, por el establecimiento de un Estado autonómico, que incluye formalmente en su organización a las autonomías departamentales e indígenas (Stefanoni, 2011:32). Estas reformas cumplen con ser el producto de una realidad boliviana históricamente muy rica en cuanto su diversidad étnica y cultural, una diversidad que fue ignorada y denostada durante muchos años por los grupos dominantes que no reconocían como legítima a la diversidad étnica indígena. $\mathrm{Y}$ aunque la diversidad étnica y social hoy es reconocida formalmente por el Estado Nacional-Popular, en realidad históricamente no se puede entender a Bolivia (o al mismo Ecuador) sin considerarla como producto de "una sumatoria de modos de producción, lógicas de acumulación, construcciones distintas de autoridad política y de esquemas simbólicos de interpretación del mundo" (Natanson, 2007:161). Sería un error considerar a los étnico y lo indígena como una manifestación del pasado, como un objeto 
de culto histórico, sino más bien se debe entender como la expresión más acabada y actual de un grupo diverso pero que encuentra su identidad en las herencias milenarias que poseen. Por otro lado, sería también erróneo pensar que las identidades indígenas son las únicas legítimas en la Bolivia actual, sino que más bien debe entenderse que a su interior coexisten tres grandes identidades culturales: la mestiza, la aymara y la quechua, además de otras 32 identidades más pequeñas. Cada una de estas posee su legitimidad y sus propias características culturales que las hacen todas valiosas y genuinas (Natanson, 2007:161).

En Bolivia la nación ha sufrido un drástico vuelco, hasta el punto que el componente indígena se ha vuelto el eje más importante de la vida política en el Estado y la fuente más importante de donde emergen los discursos que alimenta su proceso revolucionario. En este sentido, el nacionalismo boliviano se ha revestido de los movimientos indígenas pero también recupera los aportes del histórico movimiento obrero, de las clases medias progresistas, y de la inteligencia indígena y mestiza (Natanson, 2007:163). Todos estos caracteres hacen de la nación boliviana actual, una nación plural e incluyente, de una nación que en condiciones de respeto y de igualdad, se ocupa de la protección de todos sus integrantes independientemente de su filiación étnica y cultural. En este sentido el sujeto colectivo de transformación que se ha creado en Bolivia es un sujeto plural "un conglomerado de identidades y movimientos sociales con predominio de lo étnico, los pueblos indígenas, quienes son interpelados como sujetos de un proyecto de reconfiguración de la comunidad política que ya no es concebida como "una nación" sino como una articulación de naciones originarias" (Mayorga, 2006:10).

En el caso de Ecuador, encontramos que al igual que en el caso de Bolivia, la aportación del componente indígena ha sido fundamental en su proceso de transformación. En este sentido, la presencia indígena ha cuestionado las ideas tradicionales sobre ciudadanía, provocando transformaciones en el contenido propiamente constitucional y en la propia definición del Estado para pasar a ser un ente "plurinacional". De igual manera se reconoce a las comunidades indígenas como entidades fundamentales que poseen derechos específicos de acuerdo con sus condiciones particulares (Correa, 2012:99). Así, tenemos que en los Estados Nacional-Populares se ha impulsado la construcción de Estados Plurinacionales en los que priva la intención de posibilitar mediante la organización política la descolonización de los pueblos indígenas, a través del reconocimiento de su autonomía territorial, de la creación de un pluralismo jurídico incluyente y de considerarlos como una parte esencial del Estado (Stefanoni, 2011:32) (Hidalgo, 2012:167). En este sentido esta política tiende a acabar con la colonialidad y con el racismo, dos fenómenos que históricamente tuvieron un fuerte asiento en las sociedades latinoamericanas.

Finalmente, en términos de aportes ideológicos sustantivos a los proyectos de los Estados Nacional-Populares, lo plurinacional ha aportado críticas centrales a la concepción del mercado como gran mecanismo regulador de la sociedad, al cuestionamiento de fondo de la colonialidad y la discriminación, al fortalecimiento de la democracia participativa mediante la inclusión directa de las comunidades en la toma de decisiones estatales y como un asiento fundamental en la búsqueda de la soberanía nacional ante los poderes económicos y políticos transnacionales (Hidalgo, 2012:168). 


\section{Conclusiones}

Al entrar en la parte final de este trabajo, cabe hacer una recapitulación de lo que en él sostenemos. En primer lugar sostenemos que son equivocadas las caracterizaciones que desde la derecha y algunos sectores de la izquierda se han hecho de los gobiernos nacionalpopulares. Desde la derecha, la caracterización se ha intentado haciendo uso de la categoría de populismo y dándole a ésta un contenido semántico peyorativo. Desde la perspectiva neoliberal la democracia liberal y representativa asentada en la economía de mercado, sería sinónimo de buen gobierno. Y lo equivalente a mal gobierno sería todo lo contrario a esto, que abusivamente se engloba en el término de "populismo". 5 Desde la izquierda, estos gobiernos progresistas se han convertido en "un problema epistemológico" pues encubren la naturaleza neoliberal que contienen. Desde esta perspectiva, no habría diferencia entre Rafael Correa y Álvaro Noboa, entre Chávez o Maduro y Henrique Capriles. He aquí una tergiversación del análisis que tiene conclusiones políticas graves: no sucedería nada de gran importancia si el día de mañana las derechas en los países examinados retomaran el control del gobierno.

Por el contrario, en este trabajo se sostiene que los procesos políticos latinoamericanos, en particular en los tres países que aquí analizamos, existen procesos revolucionarios de características novedosas. En estos procesos revolucionarios, lo que se busca es desmantelar el neoliberalismo y sustituirlo por un orden posneoliberal. En el auge del neoliberalismo, se caracterizó a la implantación de esta nueva forma de acumulación capitalista como una "revolución conservador o neoconservadora". Consideramos abusiva esta acepción del término revolución, porque "revolución" involucra una transformación esencial de una sociedad en un sentido progresivo. El sentido de las grandes transformaciones neoliberales fue una involución de lo que el capitalismo keynesiano y de Estado de bienestar había construido. Fue una vuelta, mutatis mutandis, al capitalismo liberal tal como existía antes de las grandes luchas obreras, la revolución soviética y la crisis mundial de 1929.

Lo que hoy observamos en los países andinos en los cuales se están construyendo Estados de carácter nacional-popular, es un fenómeno progresivo porque está desmantelando lo que el neoliberalismo construyó de manera regresiva en relación a la forma keynesiana de acumulación capitalista. De esta manera lo que observamos en los tres países referidos, es la emergencia de nueva cuenta del Estado como rector de la vida económica y política del país. Ello distingue a estos procesos de manera sustancial con respecto al neoliberalismo, que vio en el Estado "el problema y no la solución". El modelo económico neoliberal ha sido gradualmente desmantelado y sustituido por una economía mixta que concibe al desarrollo ciertamente como crecimiento del PIB, pero también como disminución de la desigualdad y la pobreza (Correa, 2014). Como lo hemos sustentado con datos, los procesos nacional-populares han implicado una significativa inclusión de grandes sectores

\footnotetext{
${ }^{5}$ En anteriores oportunidades hemos ensayado esta crítica a la caracterización de los procesos nacional populares como populistas. Véase Figueroa y Moreno (2008), Figueroa (2009), Figueroa (2010a), Figueroa (2010b), Figueroa y Moreno (2010), Moreno y Figueroa (2013)
} 
sociales en los beneficios de la renta nacional, cambiando la calidad de vida de millones de personas. En Bolivia y Ecuador, países de significativa población indígena, se ha revolucionado la manera en que se concibe el Estado nacional cambiándolo a uno de carácter plurinacional y pluricultural. De igual manera se han revolucionado las relaciones que antaño se mantenían entre la población blanca y mestiza con respecto a los pueblos indígenas. Y la nación, diversa y plural, es concebida como independiente frente a cualquier hegemonía particularmente la estadounidense. Es en este sentido que la política exterior de estos países apunta a la creación de bloques regionales, empezando por la integración latinoamericana, a través de los cuales se busca un cambio de la correlación de fuerzas con respecto a los países centrales y hegemónicos. En ese sentido lo nacionalpopular se conjuga con lo antiimperialista.

Independientemente de los asuntos de carácter programático, lo que resulta esencial para caracterizar como revolucionarios a los procesos aquí examinados y no una simple vuelta al desarrollismo keynesiano, es la cuestión de la participación popular. Y con respecto a esto último, conviene no olvidar que los tres procesos aquí analizados son el resultado de vastas movilizaciones populares que le imprimen a dichos procesos un sello ineludible. Son procesos pues, marcados por el precedente popular que incluso determina que los mismos tengan al menos un horizonte poscapitalista. Y el precedente popular ha determinado una nueva composición social en el gobierno que termina por iluminar con sus colores al resto del Estado. Es indudable en los tres casos examinados, que los gobiernos nacionalpopulares desplazaron del gobierno del Estado a la cúspide de la clase dominante. He aquí pues un rasgo importante que contribuye a caracterizar a los procesos aquí examinados, como procesos revolucionarios. Y una vez en el gobierno -no sin contradicciones, incoherencias y limitaciones-, las fuerzas que lo conducen se apoyan en la movilización popular, fomentan la participación de masas -como claramente sucede en Venezuela con los Consejos Populares-, y se asientan en una democracia que ha recurrido a menudo a los referéndums o consultas populares para poder refrendar su legitimidad.

América latina es la única región en el mundo, en donde la crisis neoliberal se ha traducido en una crisis hegemónica neoliberal de diversas magnitudes y profundidades. Es la conjunción de ambas crisis lo que han desencadenado vastas movilizaciones populares sin las cuales no podría explicarse la emergencia de los gobiernos nacional-populares. $\mathrm{He}$ aquí pues, la cuestión clave para analizar con respecto a dichos gobiernos. 


\section{Bibliografía}

ACOSTA, Alberto (2010), "Maldiciones que amenazan a la democracia" en Revista Nueva Sociedad No. 229, septiembre-octubre de 2010, Buenos Aires, Argentina, pp. 42-60.

ALTMAN, David (2010), "Plebiscitos, referendos e iniciativas populares en América Latina: ¿mecanismos de control político o políticamente controlados?” en Perfiles latinoamericanos, año 18, número 35, enero-junio de 2010, pp. 9-34.

ALVARADO, Neritza (2004), “Gestión social, pobreza y exclusión en Venezuela a la luz de las misione sociales. Balance y perspectivas (2003-2004)" en kRevista Venezolana de Análisis de Coyuntura, Vol. X, No. 2 (jul-dic), pp. 25-56.

APONTE, Guillermo (2006), La inversión prudente, Fundación Milenio, La Paz, Bolivia.

CHAVES, Carlos Alberto (2010), "La inserción internacional de Sudamérica: la apuesta por Unasur" en Íconos. Revista de Ciencias Sociales, No. 38, Quito, septiembre 2010, pp. $29-40$.

CORREA, Rafael (2014). Discurso ante el V Foro Regional Esquipulas en Guatemala. Guatemala, 19 de agosto de 2014. http://www.tugentelatina.com/m/articles/view/Discursode-Rafael-Correa-en-el-V-Foro-Regional-de-Esquipulas-en-Guatemala\#.VD63Slfp-4o

D’ELIA, Yolanda y Cristyn QUIROZ (2012), “Las misiones sociales: ¿una alternativa para superar la pobreza?", citado en Vanesa y Cartaya y Nino Gianforchetta: "El futuro de la democracia en Venezuela" en Anja y Moira Suazo (editoras): Democracias en transformación. ¿Qué hay de nuevo en los nuevos Estados andinos?, Friederich-EbertStiftung Bolivia, Ecuador, Venezuela, La Paz, 2012.

Entrevista a Rafael Correa en New Left Review, No. 77 Septiembre-Octubre 2012, London, pp. 89-104.

FEBRES, María y Bernardo MÁRQUEZ (2006), "A Statistical Aproach to Asses Referendum Results: the Venezuelan Recall Referendum", en International Statical Review, Volume 74, Number 215-389, http://projecteuclid.org/DPubS?verb=Display\&version=1.0\&service=UI\&handle=euclid.isr /1165245390\&page $=$ record

FIGUEROA IBARRA, Carlos y Octavio MORENO VELADOR (2008), "Populismo: la nueva bestia negra en América latina. La visión reaccionaria del cambio político actual" en Revista Bajo el Volcán No. 13. Revista Semestral de Ciencias Sociales, Posgrado de Sociología. Instituto de Ciencias sociales y Humanidades "Alfonso Vélez Pliego" de la Benemérita Universidad Autónoma de Puebla. Año 7. 2008. ISSN: 1870-5642

FIGUEROA IBARRA, Carlos (2009). "Izquierda y gobierno en los países andinos. ¿Populismo o revolución?” (2009) En Álvarez Aragón Virgilio y Edmundo Urrutia 
(Editores). Sobre populismo y democracia en América latina. FLACSO Guatemala, Guatemala 2009.

FIGUEROA IBARRA, Carlos (2010 a), ¿En el umbral del posneoliberalismo? Izquierda y gobierno en América latina”. F\&G editores, FLACSO Guatemala. Guatemala, C.A. 2010. ISBN: 978-99939-84-05-4.

FIGUEROA IBARRA, Carlos (2010 b), "La reacción conservadora en América latina". Cambio Político en América latina. Estado, democracia y políticas sociales. Secretaría de la Paz, Presidencia de la República. Guatemala C.A.

FIGUEROA IBARRA, Carlos y Octavio H. MORENO (2010), "La Contraofensiva conservadora en América latina". Revista Papeles de Trabajo No19-Junio 2010 - ISSN 1852-4508. Centro de Estudios Interdisciplinarios en Etnolingüística y Antropología SocioCultural. Universidad de Rosario, Argentina.

GONZÁLEZ, Edmundo (2006), "Las dos etapas de las política exterior de Chávez" en Revista Nueva Sociedad, Num. 205 Septiembre/octubre 2006, Buenos Aires, Argentina, pp. 159-171 http://www.nuso.org/upload/articulos/3389 1.pdf.

GRAMSCI, Antonio (1999), "Cuadernos de la Cárcel. Tomo 5", Editorial Era-BUAP, México.

GUDYNAS, Eduardo (2009), "Diez tesis urgentes sobre el nuevo extractivismo. Contextos y demandas bajo el progresismo sudamericano actual" en AAVV: Extractivismo, política y sociedad, CAAP/CLAES/Fundación Rosa Luxemburgo, Quito.

HERNÁNDEZ, Virgilio y Fernando BUENDÍA (2011), "Ecuador: avances y desafíos de Alianza PAÍS" en Revista Nueva Sociedad, No. 234, julio-agosto de 2011, ISSN: 02513552, pp. 129-142.

HIDALGO, Francisco (2012), "Contrahegemonía y buen vivir en la fase posneoliberal" en Revista Herramienta, No.52, Buenos Aires, Argentina, pp. 163-180, http://www.herramienta.com.ar/revista-herramienta-n-52/contrahegemonia-y-buen-viviren-la-fase-posneoliberal

LAVAUD, Jean Pierre (2007), "Bolivia; ¿un futuro político hipotecado?" en Revista Nueva Sociedad, No. 209, Mayo-junio 2007, Buenos Aires, Argentina, pp. 142-159, http://www.nuso.org/upload/articulos/3435 1.pdf

LÓPEZ MAYA, Margarita (2010), "Venezuela: once años de gestión de Hugo Chávez Frías y sus fuerzas bolivarianas (1999-2010)" en Revista Temas y Debates, año 14, No. 20, octubre 2010, pp. 197-226

LÓPEZ MAYA, Margarita (2011), "Venezuela entre incertidumbres y sorpresas" en Revista Nueva Sociedad, No. 235, septiembre-octubre 2011, pp. 4-16, http://www.nuso.org/upload/articulos/3793_1.pdf 
MAYORGA, Fernando (2006), "El gobierno de Evo Morales: entre nacionalismo e indigenismo" en Revista Nueva Sociedad, núm. 206, noviembre-diciembre, ISSN:02513552. Pp. 4-13

MONSALVE, Yoana y Luis Gerardo GABALDÓN (2012), "Seguridad ciudadanía, planificación y discurso político en Venezuela" en Revista Espacio Abierto, Vol. 21, No. 3 (julio-septiembre, 2012), pp. 502-518.

MORENO, Octavio Humberto y Carlos Alberto FIGUEROA IBARRA (2013). "La manipulación del miedo y el espejo populista". Íconos. Revista de Ciencias Sociales. Num. 45, Quito, mayo 2013, pp. 33-47 Facultad Latinoamericana de Ciencias Sociales-Sede Académica de Ecuador. ISSN: 1390-1249. pp33-47.

NATANSON, José (2007), "Las reformas pactadas. Entrevista a Álvaro García Linera" en Revista Nueva Sociedad, No. 209, mayo-junio 2007, Buenos Aires, Argentina, pp. 160-172, http://www.nuso.org/upload/articulos/3436_1.pdf

PIZARRO, Roberto (2005), “Agenda económica propia” en Revista Nueva Sociedad, Núm. 199 Septiembre Octubre 2005, Buenos Aires, Argentina, pp. 120-140, http://www.nuso.org/upload/articulos/3288 1.pdf

PORTANTIERO, Juan (1981), "Los usos de Gramsci”, Folios Ediciones, México D.F

RODRÍGUEZ, Pedro (2010), "Venezuela: del neoliberalismo al socialismo del siglo XXI" en Política y Cultura, Otoño 2010, nùm. 31, pp. 187-211.

SANAHUJA, José (2008), "Del regionalismo abierto al regionalismo post-liberal". Crisis y cambio en la integración en América Latina", Anuario de Investigación, IEEE, Madrid.

SOTO, Roberto (2013), “América Latina. Entre la financiarización y el financiamiento productivo" en Revista Problemas del Desarrollo, No. 173, abril-junio 2013, Caracas, Venezuela, pp. 57-78.

STEFANONI, Pablo (2007), "Siete preguntas y siete respuestas sobre la Bolivia de Evo Morales" en Revista Nueva Sociedad, No. 209, mayo-junio 2007, Buenos Aires, Argentina, pp. 46-65, http://www.nuso.org/upload/articulos/3429_1.pdf

STEFANONI, Pablo (2011), "Bolivia hoy: rupturas, inercias y desafíos" en Revista de Estudios Bolivianos, Vol. 18, 2011.

STEFANONI, Pablo (2012), "Posneoliberalismo cuesta arriba. Los modelos de Venezuela, Bolivia y Ecuador en debate" en Revista Nueva Sociedad, No. 239, mayo-junio de 2012, pp. 51-64.

SUZART DE PÁDUA, Adriana y Suzeley Kalil Mathias (2010), "Por una política de defensa común latinoamericana: la propuesta venezolana" en Íconos. Revista de Ciencias Sociales, No. 38, Quito, septiembre 2010, pp. 55-65.

VILAS, Carlos (1994), "La Democratización fundamental. El populismo en América Latina", Consejo Nacional para la Cultura y las Artes, México. 
WEISBROT, Ray y Sandoval (2009), "El gobierno de Chávez después de 10 años: Evolución de la economía e indicadores sociales", Informe Ejecutivo, Center for Economic and Policy Research, Washington, D.C. 